\title{
Relationship between heart rate recovery and inflammatory markers in patients with polycystic ovary syndrome: a cross-sectional study
}

\author{
Francesco Giallauria*1, Francesco Orio ${ }^{2,3}$, Gaetano Lombardi3, \\ Annamaria Colao ${ }^{3}$, Carlo Vigorito ${ }^{1}$, Maria Giovanna Tafuri ${ }^{4}$ and \\ Stefano Palomba ${ }^{5}$
}

\author{
Address: ${ }^{1}$ Department of Clinical Medicine, Cardiovascular and Immunological Sciences, Cardiac Rehabilitation Unit, University of Naples \\ "Federico II", Naples, Italy, ${ }^{2}$ Endocrinology, Faculty of Exercise Sciences, University of Naples "Parthenope", Naples, Italy, ${ }^{3}$ Department of \\ Molecular \& Clinical Endocrinology and Oncology, University of Naples "Federico II", Naples, Italy, ${ }^{4}$ Teaching and Methods of Sportive Activity, \\ Faculty of Exercise Sciences, University of Naples "Parthenope", Naples, Italy and 5Department of Obstetrics and Gynaecology, University of \\ Catanzaro "Magna Graecia", Catanzaro, Italy \\ Email: Francesco Giallauria* - giallauria@libero.it; Francesco Orio - francescoorio@virgilio.it; Gaetano Lombardi - gaetano.lombardi@unina.it; \\ Annamaria Colao - colao@unina.it; Carlo Vigorito - vigorito@unina.it; Maria Giovanna Tafuri - domenicotafuri@inwind.it; \\ Stefano Palomba - stefanopalomba@tin.it \\ * Corresponding author
}

Published: 2 February 2009

Journal of Ovarian Research 2009, 2:3 doi:10.1186/1757-2215-2-3

This article is available from: http://www.ovarianresearch.com/content/2/1/3

(c) 2009 Giallauria et al; licensee BioMed Central Ltd.

This is an Open Access article distributed under the terms of the Creative Commons Attribution License (http://creativecommons.org/licenses/by/2.0), which permits unrestricted use, distribution, and reproduction in any medium, provided the original work is properly cited.

\begin{abstract}
Background: Polycystic ovary syndrome (PCOS) is an endocrine disease closely related to several risk factors for cardiovascular disease. An abnormal heart rate recovery (HRR), an easily-obtained measure derived from exercise stress test and closely related to an increased risk for cardiovascular mortality, has been recently described in PCOS women. A subclinical increase of the inflammation markers has been also observed in the PCOS. This study was designed to study the relationships between HRR and inflammatory markers in PCOS women.
\end{abstract}

Methods: Two-hundred forty-three young PCOS patients without known risk factors for cardiovascular risk were enrolled. All patients underwent hormonal and metabolic profile, white blood cells (WBCs) count and C-reactive protein (CRP). HRR was calculated as the difference between heart rate at peak exercise and heart rate at first minute of the cool-down period. Abnormal HRR was defined as $\leq \mid 8$ beats/ min for standard exercise testing.

Results: Eighty-nine out of 243 patients presented abnormal HRR. Serum CRP ( $I .8 \pm 0.7 \mathrm{vs.} \mathrm{I.I} \pm 0.4 \mathrm{mg} /$ $\mathrm{dl}, p<0.00 \mathrm{I})$ and WBCs $\left(7.3 \pm \mathrm{I} .8\right.$ vs. $6.6 \pm \mathrm{I} .5 \mathrm{I} 0^{9}$ cells $\left./ \mathrm{l}, p<0.00 \mathrm{I}\right)$ concentrations were significantly higher in PCOS patients with abnormal versus normal HRR. HRR was significantly associated with both CRP $(r=-0.33, p<0.001)$ and WBCs $(r=-0.29, p<0.001)$, although in a stepwise multiple regression HRR resulted independently associated with CRP (beta $=-0.15 \mathrm{I}, \mathrm{p}=0.00 \mathrm{I}$ ) alone. In a logistic multivariate model, the group within the highest quartile of CRP (odds ratio $1.59,95 \% \mathrm{Cl}$ I.07-2.33) was more likely to have abnormal HRR than those within the lowest quartile.

Conclusion: Abnormal HRR and inflammatory markers are closely associated in PCOS women acting probably in concert to increase the cardiovascular risk profile of these patients. 


\section{Background}

Mounting evidences suggest that polycystic ovary syndrome (PCOS) is a complex endocrine-metabolic disease strictly associated with long-term cardiovascular risk [1,2]. In fact, PCOS women, even at young age, have a clustering of cardiovascular risk factors [3-7] suggesting that they represent a group with an increased risk for developing early-onset cardiovascular disease $[2,8]$.

Heart rate recovery (HRR) is an easily-obtained measure derived from exercise stress test and is defined as the fall in heart rate during the first minute after maximal exercise [9]. The underlying mechanisms by which slow HRR after exercise is associated to an increased risk for cardiovascular mortality [10] are not fully understood. Because the rapid decrease in heart rate immediately after exercise is primarily due to vagal reactivation [11-13], slow HRR may be indicative of decreased autonomic nervous system activity.

In a recent study, PCOS women showed slower HRR when compared to healthy controls [14]. Notably, slower HRR was inversely associated to body mass index (BMI) and to markers of insulin resistance, suggesting a close and complex relationship between autonomic function and glucose metabolism in PCOS women [2,14].

Inflammation plays a key role in the pathophysiological mechanism of atherosclerosis $[15,16]$ and cardiovascular disease [17]. Several inflammation markers, such as Creactive protein (CRP), interleukin 6 , soluble intercellular adhesion molecule type 1 , and white blood cells (WBCs) count, are found to be significant predictors of the risk of coronary heart disease and future cardiovascular events [18]. Inflammation may also be associated with the metabolic syndrome $[19,20]$ and increases WBCs count [21].

Cross-sectional studies have suggested that cardiac autonomic nervous activity, as assessed by heart rate variability, is related to inflammatory markers such as CRP and WBCs count $[22,23]$. Experimental studies reported that vagal nerve stimulation can modulate inflammatory cytokines through the cholinergic anti-inflammatory pathway [24,25], thus suggesting that HRR may be related to inflammatory markers.

Based on these considerations, the current study was designed to study the relationships between HRR and inflammatory markers in a population of women with PCOS.

\section{Methods \\ Study design}

Two-hundred forty-three PCOS patients were recruited at the Department of Molecular and Clinical Endocrinology and Oncology in Naples (Italy) among those who consecutively visited the ambulatory from January 2005 to March 2008.

All PCOS patients achieved the European Society for Human Reproduction and Embryology/American Society for Reproductive Medicine criteria for the PCOS diagnosis [26]. Polycystic ovaries were identified by transvaginal ultrasonography examination [26] and hirsutism by Ferriman-Gallwey score $>8$.

Exclusion criteria included pregnancy, glucose intolerance [as screened by a 2-hour oral glucose tolerance test (OGTT)] and diabetes, hypothyroidism, hyperprolactinemia, Cushing's syndrome, non-classical congenital adrenal hyperplasia, and use of oral contraceptives, glucocorticoids, antiandrogens, ovulation induction agents, antidiabetic, antipsychotic and antiobesity drugs or other hormonal drugs and antihypertensive within the previous 6 months. Subjects with neoplastic, hepatic, respiratory and any cardiovascular disorder or other concurrent medical illness (i.e. respiratory and heart failure and renal disease) were also excluded from the study.

The study was conducted according to the guidelines of the Declaration of Helsinki, and the Institutional Ethical committee approved the study protocol. The purpose of the protocol was explained to each subject, and written informed consent was obtained from each patient before the screening. The study had no external funding source.

\section{Biochemical Assays}

All blood samples were obtained in the morning between $08.00 \mathrm{~h}$ and $09.00 \mathrm{~h}$ after an overnight fasting during the early follicular phase (2nd-4th day) of progesteroneinduced menstrual cycle. Blood samples were collected into tubes containing EDTA after a 30-min resting period in the supine position. All blood samples were immediately centrifuged at $4^{\circ} \mathrm{C}$ for $20 \mathrm{~min}$ at $1600 \mathrm{~g}$, and stored at $-20^{\circ} \mathrm{C}$ until assayed.

Plasma LH, FSH, prolactin (PRL), estradiol (E2), P, 17 $\alpha$ hydroxyprogesterone (17-OH-P), T, androstenedione $(\Delta 4)$, and DHEA-S levels were measured by specific radioimmunoassays (RIA) as previously described [3-6]. The levels of SHBG were measured using an IRMA [3-6], and the free androgen index (FAI) was calculated [T(nmol/l)/ SHBG $(\mathrm{nmol} / \mathrm{l}) \times 100]$.

Blood insulin and glucose levels were measured by a solid-phase chemiluminescent enzyme immunoassay and the glucose oxidase method, respectively [3-6]. The glucose and insulin areas under curve (AUC) for glucose $\left(\mathrm{AUC}_{\mathrm{GLU}}\right)$ and for insulin $\left(\mathrm{AUC}_{\mathrm{INS}}\right)$, and the $\mathrm{AUC}_{\mathrm{GLU}} /$ 
$\mathrm{AUC}_{\mathrm{INS}}$ ratio [27], in response to the OGTT were also calculated.

The lipid profile consisted of serum total cholesterol (TC), high-density lipoprotein-cholesterol (HDL-C), low-density lipoprotein-cholesterol (LDL-C) and triglycerides (TG) levels as previously described [3-6]. WBCs count and CRP were measured as previously described [4,7]. Interand intra-assay coefficients of variation were $<5 \%$ for all blood variables.

\section{Cardiopulmonary exercise test and HRR evaluation}

PCOS women underwent a symptom-limited CPX with Bruce treadmill protocol [6]. Heart rate (HR) and blood pressure (BP) at baseline and peak exercise, heart rate 1 minute into a walking cool-down period $(1.7 \mathrm{mph}$ at $0 \%$ grade), and treadmill speed and grade at peak exercise were recorded as previously reported [14].

HRR was calculated as the difference between heart rate at peak exercise and heart rate at first minute of the cooldown period.

Abnormal HRR, determined in our population by finding the maximum value for the log-rank chi-square test statistic for all possible cutoff points across percentiles, was defined as $\leq 18$ beats/min [9].

Respiratory gas exchange measurements were obtained breath-by-breath with use of a computerized metabolic cart (Vmax 29C, Sensormedics, Yorba Linda, CA) as previously described [6].

\section{Statistics}

Data are expressed as mean \pm standard deviation for continuous variables and as counts and proportions for cate- gorical variables. Two group comparisons were performed using independent Student's t tests for continuous variables and the chi-square test for categorical variables. CRP values were log transformed because of non-normal distribution. Pearson's correlations, stepwise multiple regression analysis, and analysis of variance were used to determine the relation between HRR and inflammatory markers. The selection of variables for entrance into the multivariate model was based on the univariate analysis. We tested potential collinearity among covariates using Pearson's correlations. After these evaluations, we selected the non-collinear variables for multivariable models: age, $\mathrm{BMI}, \mathrm{AUC}_{\mathrm{INS}}$, fasting glucose, TC, HDL-C, TG, $\mathrm{HR}_{\mathrm{REST}}$, and $\mathrm{VO}_{2 \text { peak }}$. Logistic regression was used to evaluate the association between abnormal HRR (yes or no) and quartiles of CRP and WBCs count (categorical data). Statistical significance was set at $\mathrm{p}<0.05$ for all data. Statistical analyses were performed using SPSS version 13.0 (SPSS, Inc., Chicago, IL).

\section{Results}

Group comparisons according to abnormal HRR $(\leq 18$ beats/min) are listed in Table 1. Abnormal HRR was found in 89 patients of 243 (36.6\%). Patients with abnormal HRR had significantly greater levels of CRP $(p<$ $0.001)$, and WBCs $(p<0.001)$, but not TC and LDL-C, than subjects with normal HRR.

Using Pearson's correlations, HRR was significantly associated with age $(\mathrm{r}=-0.28, \mathrm{p}<0.001)$, BMI $(\mathrm{r}=-0.49, \mathrm{p}<$ $0.001)$, AUC $_{\text {INS }}(\mathrm{r}=-0.44, p<0.001)$, HDL-C $(\mathrm{r}=0.26, p$ $<0.001)$, TG $(\mathrm{r}=-0.28, p<0.001), \operatorname{HR}_{\text {REST }}(\mathrm{r}=-0.31, p<$ $0.001), \mathrm{VO}_{2 \text { peak }}(\mathrm{r}=0.51, p<0.001), \operatorname{logCRP}(\mathrm{r}=-0.33, p$ $<0.001)$ and WBCs $(\mathrm{r}=-0.29, p<0.001)$. For anthropometrical, metabolic and cardiopulmonary profile of the PCOS population according to HRR, see Table 2.

Table I: Hormonal characteristics of the PCOS population according to HRR.

\begin{tabular}{|c|c|c|c|}
\hline Variables & $\begin{array}{l}\text { Normal HRR }(n=154) \\
(>18 \text { beats } / \mathrm{min})\end{array}$ & $\begin{array}{c}\text { Abnormal HRR }(\mathrm{n}=89) \\
(\leq 18 \text { beats } / \mathrm{min})\end{array}$ & $P$ value \\
\hline Ferriman-Gallwey score & $11.9 \pm 3.5$ & $12.1 \pm 3.4$ & 0.678 \\
\hline FSH (IU/liter) & $10.5 \pm 1.7$ & $10.1 \pm 1.6$ & 0.725 \\
\hline LH (IU/liter) & $24.2 \pm 3.3$ & $23.5 \pm 3.1$ & 0.811 \\
\hline PRL (ng/ml) & $10.5 \pm 1.3$ & $10.2 \pm 1.1$ & 0.797 \\
\hline E2 (pmol/liter) & $120 \pm 30.5$ & $118 \pm 26.1$ & 0.502 \\
\hline P (nmol/liter) & $1.2 \pm 0.4$ & $1.3 \pm 0.6$ & 0.630 \\
\hline I7-OHP (nmol/liter) & $1.6 \pm 0.3$ & $1.5 \pm 0.4$ & 0.809 \\
\hline $\mathbf{T}$ (nmol/liter) & $2.3 \pm 0.7$ & $2.5 \pm 0.5$ & 0.649 \\
\hline A (nmol/liter) & $5.1 \pm 0.7$ & $5.3 \pm 0.9$ & 0.702 \\
\hline DHEAS ( $\mu \mathrm{mol} / \mathrm{liter})$ & $4320 \pm 465$ & $4290 \pm 441$ & 0.488 \\
\hline SHBG (nmol/liter) & $27 \pm 6.2$ & $29 \pm 6.5$ & 0.549 \\
\hline FAI & $8.5 \pm 3.4$ & $8.6 \pm 3.6$ & 0.882 \\
\hline
\end{tabular}

Abbreviations: A, Androstenedione; DHEAS, dehydroepiandrosterone sulphate; E2, Estradiol; FAl, free androgen index; FSH, follicle stimulating hormone; HRR, heart rate recovery; LH, luteinizing hormone; P, progesterone; PRL, prolactin; SHBG, Sex Hormone Binding Globulin; T, testosterone; 17-OHP, I7 $\alpha$-hydroxyprogesterone. 
Table 2: Anthropometrical, metabolic and cardiopulmonary profile of the PCOS population according to HRR.

\begin{tabular}{|c|c|c|c|}
\hline Variables & $\begin{array}{l}\text { Normal HRR }(n=154) \\
(>18 \text { beats } / \mathrm{min})\end{array}$ & $\begin{array}{c}\text { Abnormal HRR }(n=89) \\
(\leq 18 \text { beats } / \mathrm{min})\end{array}$ & $P$ value \\
\hline Age (years) & $20.7 \pm 2.3$ & $23.9 \pm 1.9$ & $<0.001$ \\
\hline BMI $(\mathrm{Kg} / \mathrm{m} 2)$ & $27.3 \pm 2.9$ & $31.3 \pm 3.1$ & $<0.001$ \\
\hline WHR & $0.84 \pm 0.2$ & $0.87 \pm 0.1$ & $<0.001$ \\
\hline TC (mg/dl) & $153.3 \pm 18.1$ & $155.8 \pm 16.6$ & 0.442 \\
\hline HDL-C (mg/dl) & $44.2 \pm 7.3$ & $40.9 \pm 10.5$ & $<0.001$ \\
\hline LDL-C (mg/dl) & $89.5 \pm 8.3$ & $90.4 \pm 7.6$ & 0.593 \\
\hline TG (mg/dl) & $114.6 \pm 20.3$ & $122 \pm 22.4$ & $<0.001$ \\
\hline Fasting glucose & $93.0 \pm 6.8$ & $98.3 \pm 7.1$ & $<0.001$ \\
\hline Fasting insulin & $20.1 \pm 3.3$ & $24.2 \pm 3.7$ & $<0.001$ \\
\hline $\mathrm{AUC}_{\mathrm{GLU}}$ & $11950 \pm 2122$ & $12033 \pm 2154$ & 0.335 \\
\hline AUC INS $_{\text {IN }}$ & $16520 \pm 950$ & $17480 \pm 970$ & $<0.001$ \\
\hline AUC $_{\text {GLU/INS }}$ & $0.77 \pm 0.2$ & $0.73 \pm 0.3$ & $<0.001$ \\
\hline WBCs count $\left(\times 10^{9}\right.$ cells $\left./ \mathrm{l}\right)$ & $6.6 \pm 1.5$ & $7.3 \pm 1.8$ & $<0.001$ \\
\hline CRP (mg/dl) & $0.11(0.09-0.25)$ & $0.21(0.11-0.69)$ & $<0.001$ \\
\hline $\log C R P(\mathrm{mg} / \mathrm{dl})$ & $\mathrm{I} . \mathrm{I} \pm 0.4$ & $1.8 \pm 0.7$ & $<0.001$ \\
\hline $\mathrm{HR}_{\text {REST }}$ (beats/min) & $67.2 \pm 2.5$ & $72.1 \pm 3.9$ & $<0.001$ \\
\hline $\mathrm{VO}_{2 \text { peak }}(\mathrm{ml} / \mathrm{Kg} / \mathrm{min})$ & $26.1 \pm 3.3$ & $22.5 \pm 2.8$ & $<0.001$ \\
\hline
\end{tabular}

Abbreviations: $A \cup C_{G L U}$, area under the curve for glucose; $A \cup C_{I N S}$, area under the curve for insulin; $B M I$, body mass index; $C R P, C$-reactive protein; $\mathrm{HDL}-\mathrm{C}$, high density lipoprotein cholesterol; HRR, heart rate recovery; $\mathrm{HR}_{\mathrm{REST}}$, resting heart rate; LDL-C, low density lipoprotein cholesterol; TC, total cholesterol; TG, triglycerides; $\mathrm{VO}_{2 \max }$, maximal oxygen consumption; WBCs, white blood cells; WHR, waist to hip ratio.

In the stepwise multiple regression analysis, HRR (each 1 beat/min) was independently associated with logCRP (Table 3). Subjects were divided into quartiles according to HRR (quartile 1: < 18 beats/min; quartile 2: 18 to 24 beats/min; quartile 3: 25 to 30 beats/min; quartile 4: > 30 beats/min).

The levels of logCRP and WBCs in each quartile were 1.26 $\pm 0.2,1.13 \pm 0.2,1.05 \pm 0.1$, and $1.02 \pm 0.1 \mathrm{mg} / \mathrm{dl}$ (Figure $1)$ and $6.74 \pm 2.3,6.29 \pm 1.5,6.02 \pm 1.5$, and $5.77 \pm 1.3 \times$ $10^{9}$ cells/l (Figure 2 ) in quartiles 1 to 4 , respectively. There were significant differences among quartiles 1 to 4 for $\operatorname{logCRP}(p<0.05)$ and WBCs count $(p<0.05)$.

Table 3: Stepwise multiple regression analysis for log C-reactive protein.

\begin{tabular}{llll}
\hline Variables & $\beta$ Coefficient & SE & $P$ value \\
\hline HRR $^{*}$ & -0.151 & 0.001 & 0.001 \\
Fasting glucose & 0.039 & 0.001 & 0.005 \\
AUC $_{\text {INS }}$ & -0.136 & 0.001 & 0.001 \\
$\mathrm{BMI}$ & 0.126 & 0.003 & 0.001 \\
$\mathrm{VO}_{2 \max }$ & -0.139 & 0.001 & 0.001 \\
$\mathrm{HDL}-\mathrm{C}$ & -0.177 & 0.001 & 0.001 \\
TG $_{\text {HR }}$ & -0.141 & 0.001 & 0.001 \\
& 0.108 & 0.002 & 0.001 \\
\hline
\end{tabular}

Regression analysis included age, BMI, TC, HDL-C, LDL-C, TG, fasting glucose, $A \cup C_{I N S}, H R_{R E S T}, H R R$, and $\mathrm{VO}_{2 \max }$ as covariates.

Abbreviations: $A \cup C_{\mid N S}$, area under the curve for insulin; BMI, body mass index; HDL-C, high density lipoprotein cholesterol; $\mathrm{HR}_{\mathrm{REST}}$, resting heart rate; HRR, heart rate recovery; TC, total cholesterol; TG, triglycerides; $\mathrm{VO}_{2 \max }$, maximal oxygen consumption. *Each I beat/min.
To evaluate the association between abnormal HRR and inflammatory markers, subjects were divided into quartiles according to logCRP and WBCs count. In a logistic multivariate model (adjusted for age, BMI, TC, HDL-C, $\mathrm{TG}$, fasting glucose, $\mathrm{AUC}_{\mathrm{INS}}, \mathrm{HR}_{\mathrm{REST}}$ and $\left.\mathrm{VO}_{2 \text { peak }}\right)$ the group within the highest quartile of log CRP and WBCs count was more likely to have abnormal HRR than the group within the lowest quartile of log CRP and WBCs count (Table 4).

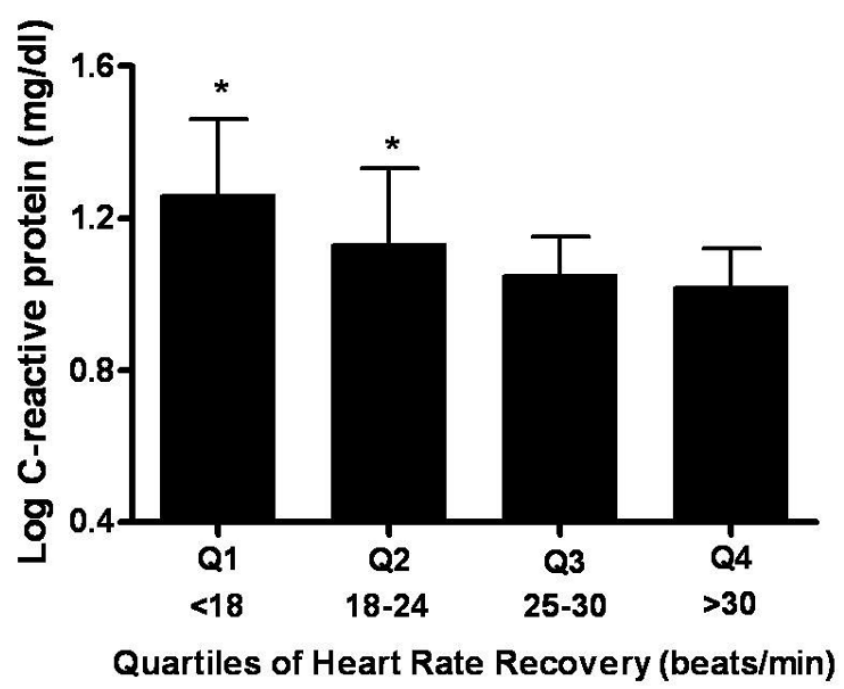

Figure I

Mean comparison of logCRP by quartile (Q) of HRR. *Significantly different from Q4 $(p<0.05)$. 


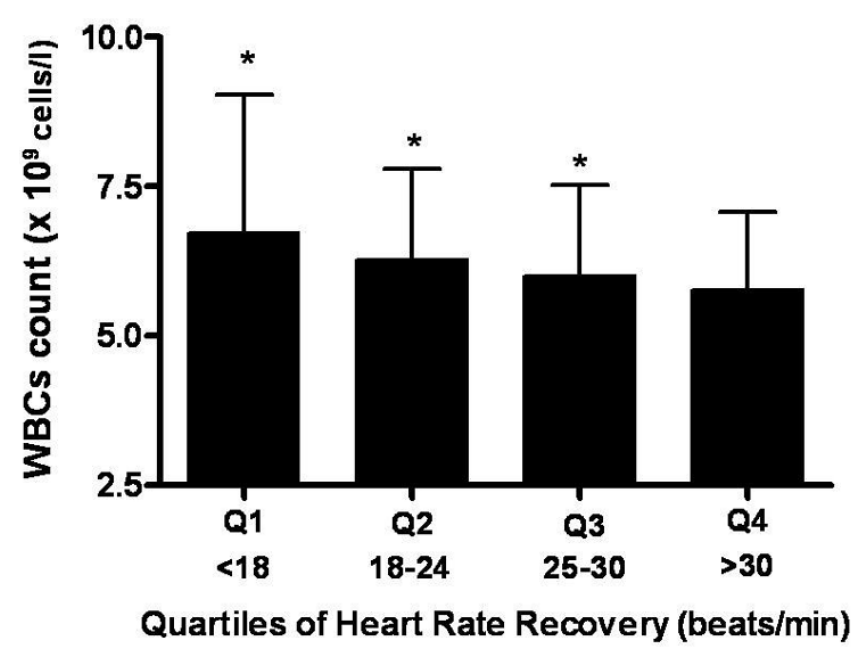

Figure 2

Mean comparison of white blood cells (WBCs) count by quartile (Q) of heart rate recovery (HRR). *Significantly different from Q4 $(p<0.05)$.

\section{Discussion}

This study describes a significant association between post exercise slow HRR and increased levels of inflammatory markers in young PCOS women.

Post exercise HRR has been demonstrated as a risk factor for cardiovascular and all-cause mortality in healthy adults $[10,28,29]$, in individuals with CVD [30] in individuals with risk factors for CVD $[31,32]$ and in men with diabetes [33]. HRR is positively associated with insulin sensitivity as measured with a hyperinsulinemic-euglycemic clamp and metabolic syndrome in elderly men [34] as well as in middle-aged men and women [35-38].

HRR has also been found to be associated with individual components of the metabolic syndrome, such as blood glucose [36] low HDL-C [34,35] and resting systolic and diastolic blood pressure [35]. Panzer et al. [36] demonstrated a strong inverse relationship between fasting plasma glucose and HRR even at non-diabetic levels among middle-aged healthy men and women. Moreover, HRR has been shown to be inversely associated with triglyceride/HDL-C ratio in middle-aged healthy men and women [37].

Although IR is not a key criterion to diagnose PCOS [26], there is a wide consensus that subjects with PCOS are more insulin resistant than healthy women. IR has been found to be significantly associated with impaired cardiopulmonary functional capacity $[6,7,38]$. Moreover, abnormal HRR was significantly associated to BMI and to $\mathrm{AUC}_{\text {INS }}$ (a powerful marker of IR), suggesting that impaired glucose metabolism in young overweight PCOS women might be a determinant of autonomic dysfunction [14]. Unfortunately, the cross sectional nature of the present study does not allow the evaluation of a causal association between autonomic dysfunction and IR and the elucidation of the mechanisms involved in the pathogenesis of both conditions.

It is known that inflammation plays an important role in the development and progression of atherosclerosis [39], and inflammatory markers such as CRP and WBCs count are strong predictors of cardiovascular events in healthy populations as well as patients with coronary heart disease [40].

Higher CRP levels and WBCs count have been described $[4,7]$ in a wide PCOS women population suggesting an increased cardiovascular risk profile in these patients [2]. Observational studies showed a decreased autonomic nervous system activity related to inflammatory markers $[22,23]$. Recent experimental evidences suggest a role for the parasympathetic nervous system in the direct regulation of inflammation, pointing to the existence of a cholinergic anti-inflammatory reflex [24,25]. Recently, Vieira et al. [41] reported that post exercise HRR is independently associated with lower CRP in older sedentary individuals, suggesting an involvement of parasympathetic nervous system in regulating chronic inflammation

Table 4: Multivariate-adjusted odds ratios (95\% confidence interval) for abnormal heart rate recovery (HRR) by quartile of log Creactive protein (log CRP) and white blood cells (WBCs) count

\begin{tabular}{|c|c|c|c|c|}
\hline Variable & Quartile I (Reference) & Quartile 2 & Quartile 3 & Quartile 4 \\
\hline $\log C R P(m g / d l)$ & $(n=67) \leq 0.8$ & $(n=75) 0.81-1.19$ & $(n=53) 1.2-1.5$ & $(n=48) \geq 1.5$ \\
\hline Crude model & 1.00 & $1.44(1.21-1.86)$ & $2.23(1.73-2.88)$ & $3.41(2.42-4.25)$ \\
\hline Adjusted model & 1.00 & $1.19(0.81-1.63)$ & $1.34(0.93-1.99)$ & $1.59(1.07-2.33)$ \\
\hline WBCs count (x 109 cells/l) & $(n=62) \leq 5.0$ & $(n=7 I) 5.1-6.0$ & $(n=58) 6.1-7.0$ & $(n=52) \geq 7.1$ \\
\hline Crude model & 1.00 & $1.41(1.14-1.93)$ & $1.95(1.48-2.65)$ & $2.77(2.19-3.58)$ \\
\hline Adjusted model & 1.00 & $1.38(1.06-2.12)$ & $1.33(0.97-1.96)$ & $1.61(1.14-2.46)$ \\
\hline
\end{tabular}

Crude model is unadjusted. Adjusted model includes age, BMI, TC, HDL-C, TG, fasting glucose, $A \cup C_{I_{N S S}}, H_{R E S T}$, and VO ${ }_{2 p e a k}$.

Abbreviations: $A \cup C_{\mid N S}$, area under the curve for insulin; BMI, body mass index; CRP, C-reactive protein; HDL-C, high density lipoprotein cholesterol; logCRP, logarithmic transformation of CRP values; $\mathrm{HR}_{\mathrm{REST}}$, resting heart rate; $\mathrm{TC}$, total cholesterol; $\mathrm{TG}$, triglycerides; $\mathrm{VO} \mathrm{2max}_{\text {, maximal }}$ oxygen consumption; WBCs, white blood cells. 
in older adults. Moreover, it has been recently reported that the reduced cardiac adrenergic activity (evaluated by iodine-123-labeled metaiodobenzylguanidine uptake) observed in patients with glucose intolerance was associated to elevated pro-inflammatory cytokine levels [42].

The association between autonomic nervous system and systemic inflammation in young PCOS women after adjustment for common cardiovascular and metabolic confounders shed light on the complex mechanisms and the possible therapeutic strategies related to this endocrine-cardiometabolic disease.

Experimental and clinical evidences suggest that exercise training is an effective therapeutic intervention aimed at improving autonomic function as well as cardiopulmonary functional capacity [43-45]. In PCOS women, the exercise-induced improvement of cardiopulmonary and autonomic function should have been addressed to the improvement in insulin sensitivity, to the reduction in BMI, and to the powerful anti-inflammatory effect of training $[46,47]$. However, exercise training should be continued regularly in order to maintain the described beneficial effects [48].

Our previous prospective controlled data [46-48], in fact, confirmed that exercise training is effective in reducing BMI and improving insulin sensitivity markers in PCOS women, even thought no significant changes in sex hormones were observed. At this regard, it could be possible to hypothesize that the exercise induced improvement of autonomic function is mediated by BMI reduction and insulin sensitivity improvement.

Recently, Thompson et al. [49] studied the effect of weight loss on HRR in overweight and obese PCOS patients. After 10 weeks of diet, a significant improvement in HRR was observed in concert with a reduction in body weight, waist circumference, blood pressure, fasting insulin and glucose levels, HOMA score, T, FAI, and with an increase in SHBG [49]. In addition, HRR was significantly related to the reduction in body weight and waist circumference [49]. These findings demonstrated that weight loss can exert a beneficial role in reducing the cardiovascular risk in PCOS patients also improving the autonomic function [49].

Given the cross-sectional nature of the present study, it cannot be determined whether impaired autonomic function is the cause or effect of systemic inflammation. A potential limitation of our data is that we did not control for diet status, which may potentially confound the relation between HRR and inflammation markers. Because of the relation between cardiopulmonary functional capacity and HRR, strength of this study is the use of directly measured peak oxygen uptake as a covariate.

\section{Conclusion}

In young PCOS women, abnormal HRR after exercise testing is significantly and closely associated to inflammatory markers, i.e. CRP and WBCs. These findings could suggest that in women with PCOS several alterations could act in concert contributing to increase cardiovascular risk profile of these patients.

\section{Competing interests}

The authors declare that they have no competing interests.

\section{Authors' contributions}

FG, FO, GL, AC, CV, MGT and SP conceived of the study, participated in its design and coordination and drafted the manuscript. FG performed the statistical analysis. All authors read and approved the final version of the manuscript.

\section{References}

I. Ehrmann DA: Polycystic ovary syndrome. N Engl J Med 2005, 352:1223-1236.

2. Giallauria F, Orio F, Palomba S, Lombardi G, Colao A, Vigorito C: Cardiovascular risk in women with polycystic ovary syndrome. J Cardiovasc Med 2008, 9:987-992.

3. Orio F Jr, Palomba S, Cascella T, De Simone B, Di Biase S, Russo T, Labella D, Zullo F, Lombardi G, Colao A: Early impairment of endothelial structure and function in young normal-weight women with polycystic ovary syndrome. J Clin Endocrinol Metab 2004, 89:4588-4593.

4. Orio F Jr, Palomba S, Cascella T, Di Biase S, Manguso F, Tauchmanova L, Nardo LG, Labella D, Savastano S, Russo T, Zullo F, Colao A, Lombardi G: The increase of leukocytes as a new putative marker of low-grade chronic inflammation and early cardiovascular risk in polycystic ovary syndrome. J Clin Endocrinol Metab 2005, 90:2-5.

5. Cascella T, Palomba S, Tauchmanovà L, Manguso F, Di Biase S, Labella D, Giallauria F, Vigorito C, Colao A, Lombardi G, Orio F: Serum aldosterone concentration and cardiovascular risk in women with polycystic ovarian syndrome. J Clin Endocrinol Metab 2006, 91:4395-4400.

6. Orio F, Giallauria F, Palomba S, Cascella T, Manguso F, Vuolo L, Russo T, Tolino A, Lombardi G, Colao A, Vigorito C: Cardiopulmonary impairment in young women with polycystic ovary sindrome. J Clin Endocrinol Metab 2006, 9 I :2967-297I.

7. Giallauria F, Palomba S, De Sio I, Maresca L, Vuolo L, Savastano S, Lombardi G, Colao A, Vigorito C, Orio F: Inflammatory markers and visceral fat are inversely associated with maximal oxygen consumption in women with polycystic ovary syndrome. Clin Endocrinol (Oxf) in press.

8. Orio $F$ Jr, Palomba $S$, Spinelli L, Cascella $T$, Tauchmanovà L, Zullo F, Lombardi G, Colao A: The cardiovascular risk of young women with polycystic ovary syndrome: an observational, analytical, prospective case-control study. J Clin Endocrinol Metab 2004, 89:3696-367l.

9. Shetler K, Marcus R, Froelicher VF, Vora S, Kalisetti D, Prakash M, Do $D$, Myers J: Heart Rate Recovery: Validation and Methodologic issues. J Am Coll Cardiol 200 I, 38: 1980-1987.

10. Cole CR, Blackstone EH, Pashkow FJ, Snader CE, Lauer MS: Heartrate recovery immediately after exercise as a predictor of mortality. NEngl J Med 1999, 34 I: I 351-1357.

II. Imai K, Sato H, Hori M, Kusuoka H, Ozaki H, Yokoyama H, Takeda $H$, Inoue $M$, Kamada $T$ : Vagally mediated heart rate recovery after exercise is accelerated in athletes but blunted in patients with chronic heart failure. J Am Coll Cardiol 1994, 24:1529-1535.

12. Arai Y, Saul JP, Albrecht P, Hartley LH, Lilly LS, Cohen RJ, Colucci WS: Modulation of cardiac autonomic activity during and immediately after exercise. Am J Physiol Heart Circ Physiol 1989, 256:|32-|4|. 
13. Kannankeril PJ, Le FK, Kadish AH, Goldberger J]: Parasympathetic effects on heart rate recovery after exercise. J Investig Med 2004, 52:394-40I.

14. Giallauria F, Palomba S, Manguso F, Vitelli A, Maresca L, Tafuri D, Lombardi G, Colao A, Vigorito C, Orio F: Abnormal heart rate recovery after maximal cardiopulmonary exercise stress testing in young overweight women with polycystic ovary syndrome. Clin Endocrinol (Oxf) 2008, 68:88-93.

15. Alexander RW: Inflammation and coronary artery disease. $N$ Engl J Med 1994, 33 I:468-469.

16. Wilson PW, Kannel WB, Silbershatz H, D'Agostino RB: Clustering of metabolic factors and coronary heart disease. Arch Intern Med 1999, 159: I 104-II 09.

17. Lee CD, Folsom AR, Nieto FJ, Chambless LE, Shahar E, Wolfe DA: White blood cell count and incidence of coronary hart disease and ischemic stroke and mortality from cardiovascular disease in African-American and white men and women. Am J Epidemiol 200I, I 54:758-764.

18. Hoffman M, Blum A, Baruch R, Kaplan E, Benjamin M: Leukocytes and coronary heart disease. Atherosclerosis 2004, I72: I-6.

19. Kelly CC, Lyall H, Petrie JR, Gould GW, Connell JM, Sattar N: Low grade chronic inflammation in women with polycystic ovarian syndrome. J Clin Endocrinol Metab 200I, 86:2453-2455.

20. Ford ES: The metabolic syndrome and C-reactive protein, fibrinogen, and leukocyte count: findings from the Third National Health and Nutrition Examination Survey. Atherosclerosis 2003, 168:35I-358.

21. Nieto FJ, Szklo M, Folsom AR, Rock R, Mercuri M: Leukocyte count correlates in middle-aged adults: the Atherosclerosis Risk in Communities (ARIC) Study. Am J Epidemiol 1992, I36:525-537.

22. Sajadieh A, Wendelboe Nilsen O, Rasmussen V, Hein HO, Abedini S, Jorgen FH: Increased heart rate and reduced heart-rate variability are associated with subclinical inflammation in middleaged and elderly subjects with no apparent heart disease. Eur Heart J 2004, 25:363-370.

23. Jensen-Urstad M, Jensen-Urstad K, Ericson M, Johansson J: Heart rate variability is related to leukocyte count in men and to blood lipoproteins in women in a healthy population of 35 year-old subjects. J Intern Med 1998, 243:33-40.

24. Tracey KJ: The inflammatory reflex. Nature 2002, 420:853-859.

25. Borovikova LV, Ivanova S, Zhang M, Yang H, Botchkina GI, Watkins LR, Wang H, Abumrad N, Eaton JW, Tracey KJ: Vagus nerve stimulation attenuates the systemic inflammatory response to endotoxin. Nature 2000, 405:458-462.

26. Rotterdam ESHRE/ASRM-Sponsored PCOS Consensus Workshop Group: Revised 2003 consensus on diagnostic criteria and long-term health risks related to polycystic ovary syndrome. Fertil Steril 2004, 8I:19-25.

27. Tai MM: A mathematic model for the determination of total area under glucose tolerance and other metabolic curves. Diabetes Care 1994, 17:152-154.

28. Morshedi-Meibodi A, Larson MG, Levy D, O'Donnell CJ, Vasan RS: Heart rate recovery after treadmill exercise testing and risk of cardiovascular disease events (The Framingham Heart Study). Am J Cardiol 2002, 90:848-852.

29. Mora S, Redberg RF, Cui Y, Whiteman MK, Flaws JA, Sharrett AR, Blumenthal RS: Ability of exercise testing to predict cardiovascular and all-cause death in asymptomatic women: a 20-year follow-up of the lipid research clinics prevalence study. JAMA 2003, 290:1600-1607.

30. Vivekananthan DP, Blackstone EH, Pothier CE, Lauer MS: Heart rate recovery after exercise is a predictor of mortality, independent of the angiographic severity of coronary disease. J Am Coll Cardiol 2003, 42:83I-838.

31. Watanabe J, Thamilarasan M, Blackstone EH, Thomas JD, Lauer MS: Heart rate recovery immediately after treadmill exercise and left ventricular systolic dysfunction as predictors of mortality: the case of stress echocardiography. Circulation 200I, 104:1911-1916.

32. Pitsavos $\mathrm{CH}$, Chrysohoou C, Panagiotakos DB, Kokkinos P, Skoumas J, Papaioannou I, Michaelides AP, Singh S, Stefanadis Cl: Exercise capacity and heart rate recovery as predictors of coronary heart disease events, in patients with heterozygous familial hypercholesterolemia. Atherosclerosis 2004, 173:347-352.

33. Cheng YJ, Lauer MS, Earnest CP, Church TS, Kampert JB, Gibbons LW, Blair SN: Heart rate recovery following maximal exercise testing as a predictor of cardiovascular disease and all-cause mortality in men with diabetes. Diabetes Care 2003, 26:2052-2057.

34. Lind $L$, Andren $B$ : Heart rate recovery after exercise is related to the insulin resistance syndrome and heart rate variability in elderly men. Am Heart J 2002, 144:666-672.

35. Sung J, Choi YH, Park JB: Metabolic syndrome is associated with delayed heart rate recovery after exercise. J Korean Med Sci 2006, $21: 621-626$.

36. Panzer C, Lauer MS, Brieke A, Blackstone E, Hoogwerf B: Association of fasting plasma glucose with heart rate recovery in healthy adults: a population-based study. Diabetes 2002, 51:803-807.

37. Shishehbor MH, Hoogwerf BJ, Lauer MS: Association of triglyceride-to HDL Cholesterol ratio with heart rate recovery. Diabetes Care 2004, 27:936-94I.

38. Orio F Jr, Palomba S, Giallauria F, Colao A, Vigorito C: Impaired cardiopulmonary parameters in young women with polycystic ovary syndrome. Clin Endocrinol (Oxf) 2007, 66:152-153.

39. Hansson GK: Inflammation, atherosclerosis, and coronary artery disease. N Engl J Med 2005, 352:1685-1695.

40. Madjid M, Awan I, Willerson JT, Casscells SW: Leukocyte count and coronary heart disease: implications for risk assessment. J Am Coll Cardiol 2004, 44:1945-1956.

4I. Vieira VJ, Valentine RJ, McAuley E, Evans E, Woods JA: Independent relationship between heart rate recovery and C-reactive protein in older adults. J Am Geriatr Soc 2007, 55:747-75I.

42. Diakakis GF, Parthenakis FI, Patrianakos AP, Koukouraki SI, Stathaki MI, Karkavitsas NS, Vardas PE: Myocardial sympathetic innervation in patients with impaired glucose tolerance: relationship to subclinical inflammation. Cardiovasc Pathol 2008, 17:172-177.

43. Giallauria F, Del Forno D, Pilerci F, De Lorenzo A, Manakos A, Lucci $\mathrm{R}$, Vigorito C: Improvement of heart rate recovery after exercise training in the elderly. I Am Geriatr Soc 2005, 53:2037-2038.

44. Giallauria F, De Lorenzo A, Pilerci F, Manakos A, Lucci R, Psaroudaki $M$, D'Agostino M, Del Forno D, Vigorito C: Long-term effects of cardiac rehabilitation on end-exercise heart rate recovery after myocardial infarction. Eur J Cardiovasc Prev Rehabil 2006, 13:544-550.

45. Giallauria F, Lucci R, Pietrosante M, De Lorenzo A, Gargiulo G, D'Agostino M, Gerundo G, Abete P, Rengo F, Vigorito C: Exercisebased Cardiac Rehabilitation improves Heart Rate Recovery in Elderly Patients after Acute Myocardial Infarction. J Gerontol Ser A-Biol Sci Med Sci 2006, 61:71 3-717.

46. Vigorito $C$, Giallauria $F$, Palomba $S$, Cascella $T$, Manguso $F$, Lucci $R$ De Lorenzo A, Lombardi G, Colao A, Orio F jr: Beneficial effects of a structured exercise training program on cardiopulmonary functional capacity in young women with polycystic ovary syndrome. J Clin Endocrinol Metab 2007, 92:1379-1384.

47. Giallauria F, Palomba S, Maresca L, Vuolo L, Tafuri D, Lombardi G, Colao A, Vigorito C, Orio F: Exercise training improves autonomic function and inflammatory pattern in women with polycystic ovary syndrome. Clin Endocrinol (Oxf) 2008, 69:792-798.

48. Orio F Jr, Giallauria F, Palomba S, Manguso F, Orio M, Tafuri D, Lombardi G, Carmina E, Colao A, Vigorito C: Metabolic and cardiopulmonary effects of detraining after a structured exercise training program in young polycystic ovary syndrome women. Clin Endocrinol (Oxf) 2008, 68:976-98I.

49. Thomson RL, Buckley JD, Noakes M, Clifton PM, Norman RJ, Brinkworth GD: Heart rate recovery improves after weight loss in overweight and obese women with polycystic ovary syndrome. Fertil Steril 2009 in press. 